Provided for non-commercial research and education use. Not for reproduction, distribution or commercial use.

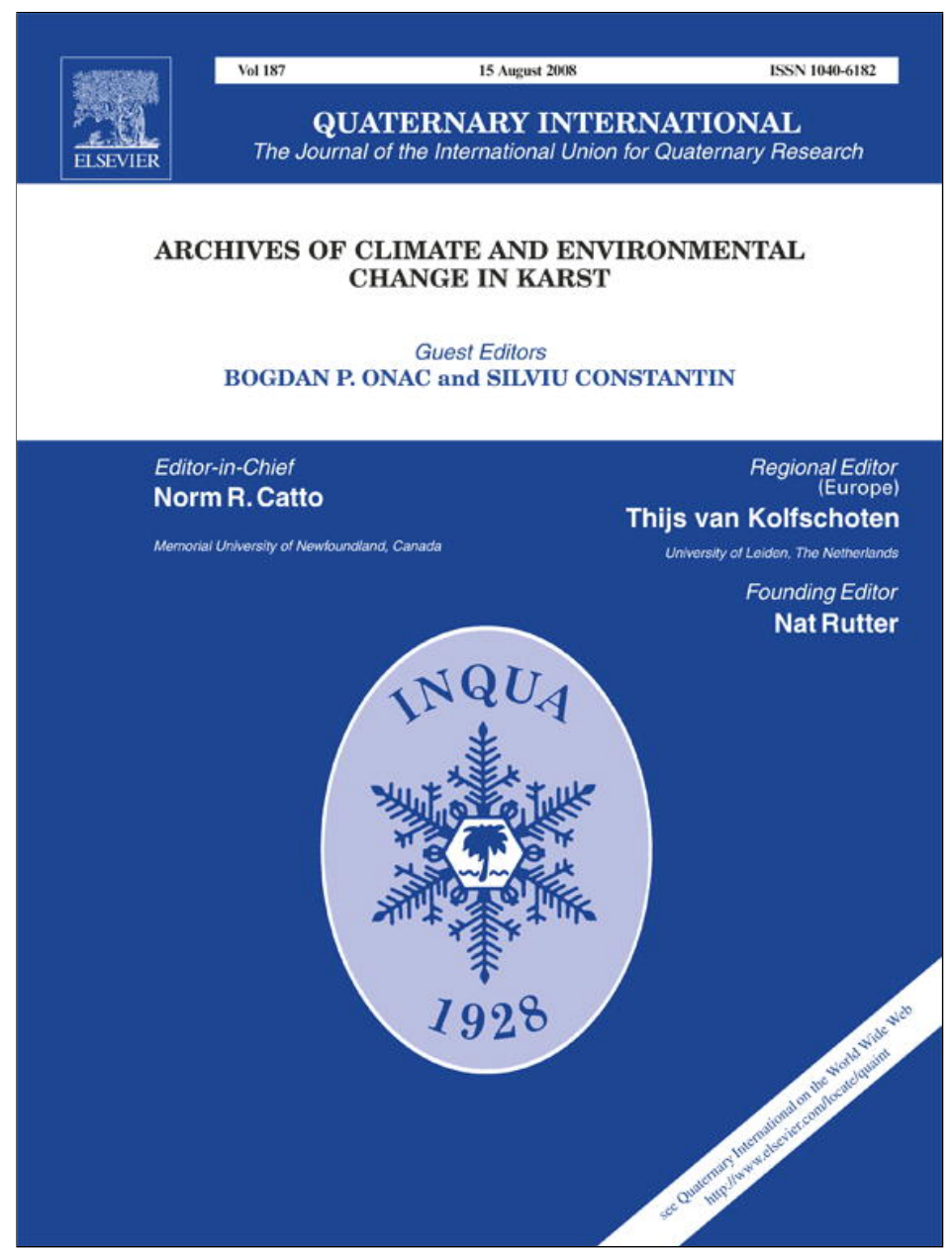

This article appeared in a journal published by Elsevier. The attached copy is furnished to the author for internal non-commercial research and education use, including for instruction at the authors institution and sharing with colleagues.

Other uses, including reproduction and distribution, or selling or licensing copies, or posting to personal, institutional or third party websites are prohibited.

In most cases authors are permitted to post their version of the article (e.g. in Word or Tex form) to their personal website or institutional repository. Authors requiring further information regarding Elsevier's archiving and manuscript policies are encouraged to visit:

http://www.elsevier.com/copyright 


\title{
Hyperspectral imaging of speleothems
}

\author{
Catherine Jex ${ }^{\mathrm{a}, *}$, Ela Claridge ${ }^{\mathrm{b}}$, Andy Baker ${ }^{\mathrm{a}}$, Claire Smith ${ }^{\mathrm{a}}$ \\ ${ }^{a}$ School of Geography, Earth and Environmental Sciences, The University of Birmingham, Birmingham B15 2TT, UK \\ ${ }^{\mathrm{b}}$ School of Computer Sciences, The University of Birmingham, Birmingham B15 2TT, UK
}

Available online 24 May 2007

\begin{abstract}
Proxy records from speleothems are used in palaeoclimatic reconstructions, as the factors controlling their growth rate, nature of their internal structure and chemical composition respond to changes in surface climate. Optical analyses of stalagmites include visual observation of stalagmite images obtained from flatbed scanners or digital cameras. Hyperspectral imaging has not been used in stalagmite research, but potentially has many advantages over standard optical imaging techniques. Hyperspectral images of a set of stalagmites have been obtained in order to demonstrate the application of hyperspectral imaging in speleothem research. Our results highlight the following: (1) Spectra obtained for these calcite stalagmites are similar between a group of stalagmites of different ages, hydrological setting within a cave and from different caves. (2) The largest differences in relative reflectance between areas of dark compact calcite (DCC) and white porous calcite (WPC) are in the range 470-590 nm (this may extend to $680 \mathrm{~nm}$ for some of the stalagmites). (3) Imaging in the near infrared (NIR) demonstrates a decrease in reflection at water absorbance wavelengths, suggesting there is potential for mapping $\mathrm{H}_{2} \mathrm{O}$.
\end{abstract}

(C) 2007 Elsevier Ltd and INQUA. All rights reserved.

\section{Introduction}

Proxy records from speleothems are increasingly used in palaeoclimatic reconstructions, as the factors controlling their growth rate and the nature of the internal structure and chemical composition of speleothems respond to changes in surface climate. Formed as part of the meteoric water cycle, speleothems are capable of recording a climatic signal smoothed by the mixing of event and stored water in the karst aquifer above the cave (Bar-Matthews et al., 1991). As such, they are capable of recording changes in climate parameters such as mean annual temperature, precipitation, or atmospheric circulation changes, and vegetation responses, back through time via a number of available proxies (McDermott, 2004). These include stable isotope ratios (Rozanski et al., 1992; McDermott, 2004), inter-annual thickness variations of growth laminae, growth rate changes (Genty et al., 2001; Tan et al., 2006), variations in trace element ratios (Ayalon et al., 1999; Roberts et al., 1999; Fairchild, 2002), organic acid content (White and Brennan, 1989; Rousseau et al., 1993) and

\footnotetext{
${ }^{*}$ Corresponding author. Tel.: + 4401214146869 .

E-mail address: cnj472@bham.ac.uk (C. Jex).
}

trapped pollen grains (McGarry and Caseldine, 2004). An area where published research is perhaps rarer is petrographical studies of stalagmites, for example, Kendall and Broughton (1978), Genty (1993), Bar-Matthews et al. (1991) and Frisia et al. (2000).Valuable information can also be obtained by examining the visual characteristics, e.g. colour and the internal structure of a stalagmite (i.e. nature of the annual/sub-annual lamina and changes in crystalline fabric and porosity), as these can give important information on the environmental conditions under which the speleothem formed (Perrette et al., 1997; Xiaoguang et al., 1998).

\subsection{Current use of optical analyses in speleothem research}

Optical analyses of stalagmites have up until now included visual observation of stalagmite images obtained from flatbed scanners or digital cameras. Although these can provide good-quality images, microscopy (under both visible and fluorescent illumination) has been required to identify finer resolved features. Subsequent digital image processing has identified such things as grey-level changes throughout individual stalagmite lamina and within a group of laminae captured under polarised visible light 
(Xiaoguang et al., 1998), luminescence properties under UV-light (Baker et al., 1993; Ribes et al., 2000), and crystalline fabric and calcite porosity (Kendall and Broughton, 1978; Genty, 1993; Frisia et al., 2000). Such studies have aided the recognition of sub-annual lamina made up of white porous calcite lamina (WPL) and dark compact calcite lamina (DCL), which together make up an annual lamination (Genty, 1993); they also identified organic acid layers (humic and fulvic acids), which may be used to determine variations in the annual growth rate (Baker et al., 1993) as well as an indicator of paleoprecipitation (Proctor et al., 2002). Further, they have identified supra-annual scale variations in "bundles" of DCL and WPL (Genty and Quinif, 1996; Genty et al., 1997) as well as the same longer term variations in fluorescence intensity (Baker et al., 1996) and wavelength (Proctor et al., 2000) and produced such things as a fluorescence index (FI) (ratio of two organic matter (OM) fluorescence intensities by fluorescence laser analyses) to identify changes in spectroscopic characteristics of stalagmite samples associated with environmental change (Perrette et al., 2005).

\subsection{Current applications of reflectance spectra in speleothem research}

Reflectance spectra have been used to identify the dominant source of colour in a collection of stalagmites (White, 1981) and it is reported by Perrette et al. (1997) in their comparison of the use of reflectance spectra with the other optical analyses mentioned above. Colour is not a tangiable object, it is merely a perception of the human eye caused by the reflection or absorption of particular wavelengths of incident light on an object. The human eye is sensitive only to the wavelengths of light reflected from an object in the region of $400-650 \mathrm{~nm}$ which provide the brain with three signals in the red, green and blue (RGB) range (as shown in Fig. 1). The colour of an object is reconstructed by the brain according to the combination of the relative intensities of these three wavelength bands (RGB) and is affected by the wavelength of the illuminating light source, as well as the absorption/reflection properties of the object being viewed, which are in turn a reflection of their chemical composition and internal structure. By capturing an image of the object under different light conditions, it is possible to present a graphical representation of the absorption/reflection spectra of an object of a certain colour.

Absorption spectra for different coloured stalagmites have been obtained previously (Fig. 1: White, 1981) showing the absorption spectra typical of common stalagmite colours. Reflective spectra of the same samples demonstrated that the location of reflectance bands of common stalagmite colours of milky yellow, orange, tan and brown were not related to those spectra obtained for oxides and hydroxides of iron, suggesting for the first time that iron oxides are not the dominant source of colour,

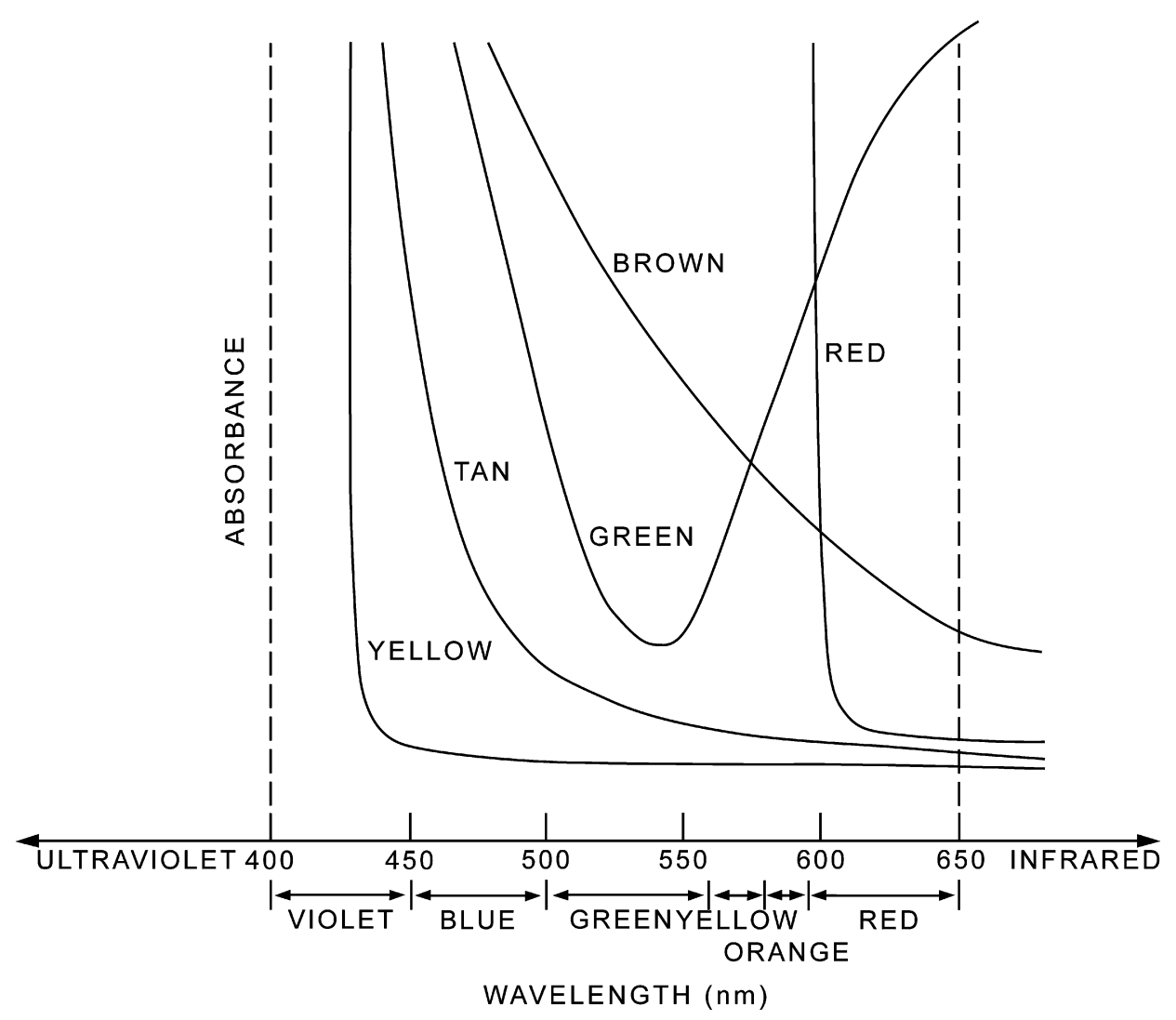

Fig. 1. Schematic spectra showing some relations between absorption curves and perceived colours (taken from White, 1981). 
indirectly suggesting that organic pigments were responsible for the common colours of these stalagmites. This was later supported by Perrette et al. (1997), and by the subsequent identification of fluorescence $\mathrm{OM}$ and other biomarkers in stalagmites. Such studies have been limited to only being able to capture reflectance spectra of stalagmites over a particular band of wavelengths in the visible part of the spectrum and so they are potentially missing a large amount of detail which if available may better aid the identification of fine sub-mm lamina and crystalline features, as well as in identification of the type of organic acids, iron oxides or inclusions and in deciding whether or not similar looking features are in fact the same in-terms of their reflective spectra. Similarly, an image captured on a standard digital camera microscope set up or flat bed scanner will produce spectra in the red, blue and green bands and so similarly mask any subtle variations that may occur within these bands or outside of these bands, i.e. beyond the visible part of the spectrum. Other limitations are the destructive nature of creating thin sections of stalagmite often used for imaging work, which may use up large portions of samples, the time it takes to capture images by microscopy when working with field of views in the order of $\mathrm{mm}$ or less (especially if multiple transects are taken), the process of moving the sample in order to take the next image and subsequently tiling images which can cause non-uniformity between images and discontinuities (Ribes et al., 2000). Ribes et al. (2000) describe the set-up of a confocal scanning laser macroscope to take photoluminescence images of speleothem microbanding. The confocal lens eliminates light from outside the focal plane which may blur any captured image, whilst the macroscope set-up allows for a much larger field of view up to $7.5 \times 7.5 \mathrm{~cm}$ (or down to $200 \times 200 \mu \mathrm{m}$ ), without loosing image resolution. However, this setup still only really allows a qualitative analysis of luminescent lamina and suffers the same lack of detail of obtained spectra as described earlier.

\subsection{Hyperspectral imaging}

Hyperspectral imaging is a technique never before used in stalagmite research, but potentially has many advantages over standard optical imaging techniques in terms of the detail of information that can be obtained from a single-image capture process.

A standard flat bed scanner or digital camera uses three filters to capture all light reflected off an object in three broad bands of wavelengths, the RGB. As such the final image is constructed by combining these three images taken in the visible range RGB bands widths, and thus can only say whether or not there is a peak in these bands. It cannot resolve spectra finer than these three broad bands. In hyperspectral imaging many more filters are used and hence the final image is constructed from many image "slices" (i.e. hundreds of image slices as opposed to just three image slices of conventional imaging techniques) taken at whatever wavelength interval is selected. These image slices can be laid out and viewed individually as in Fig. 2, or can be stacked one on top of another to produce a "Lambda Stack" or "image cube" (Fig. 3) where an area on the top image slice (from the whole image down to an individual pixel) can be selected and the reflectance intensities at each wavelength captured down through the lambda stack can be displayed graphically (Fig. 3). This means that spectra obtained by hyperspectral imaging methods (here on referred to as spectra $\mathrm{H}_{\mathrm{H}}$ ) can be resolved in much greater detail, and may show many more reflectance peaks and troughs that standard imaging could not resolve. This offers a more accurate way of classifying certain features captured by an image. Further, hyperspectral imaging can extend beyond the visible range of the spectrum, identifying features that may not be picked up by standard imaging techniques at any magnification. As such hyperspectral imaging may potentially aid the identification of fine sub-mm lamina and crystalline features, the type of organic acids, iron oxides or inclusions and establish whether similar looking features are in fact the same in-terms of their reflective spectra $_{\mathrm{H}}$.

\subsection{Current applications of hyperspectral imaging}

Hyperspectral imaging currently has wide ranging applications. GIS and remote sensing studies make use of this technology in mineral exploration and geological mapping (Gomez, 2000 and references there in). McLaugh et al. (2001) identified clay-rich altered rock in the faces of mine slopes according to their reflectance spectra, and they were then able to map areas of the slope at risk of failure. Similarly monitoring of soil erosion is possible by identification of soil moisture conditions (Haubrock et al., 2005). Applications in assessing water quality include the identification of submerged macrophytes in lakes as an indication of their trophic state and its ecosystem (Pinnel et al., 2004), as well as detection and identification of submerged aquatic vegetation in waterways, and detection and tracking of oil spills (Gomez, 2002). The technique has also been applied in pollution studies by aiding in the detection and tracking of industrial plumes (Hamid Muhammed, 2005), and the agriculture industry applies this technology for the purposes of crop management, e.g. quantification of fungal diseases in crops (Hamid Muhammed, 2005). Other applications may include assessment of road characteristics and the detection and identification of vehicles (Gomez, 2002) in the transport industry, as well as applications in medical imaging (Hidovic and Claridge, 2006).

As with other geological/soil applications, variations in parameters such as calcite fabric and porosity, OM, trace element and stable isotope concentrations and fluid inclusion density of speleothems may all carry characteristic reflectance spectra $_{\mathrm{H}}$. This paper aims to demonstrate the method of collecting hyperspectral images 


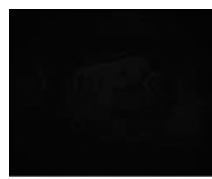

image 420

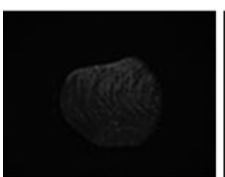

image 460

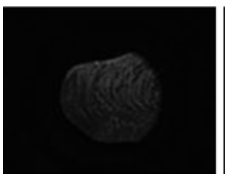

image 500

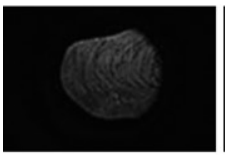

image 580

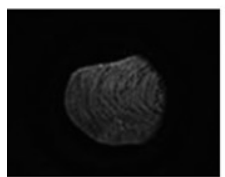

image620

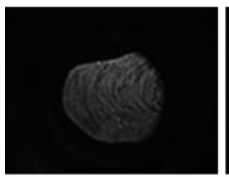

image660

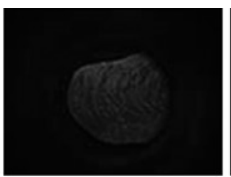

image425

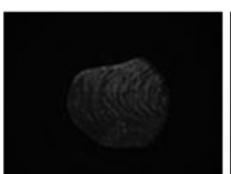

image465

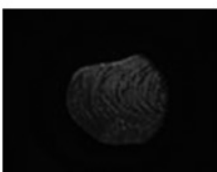

image505

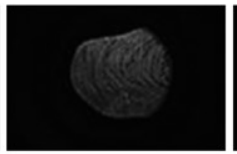

image 585

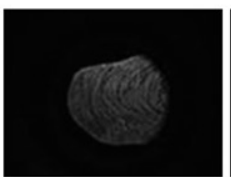

image 625

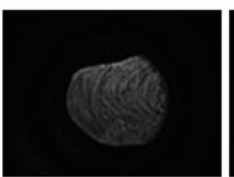

image665

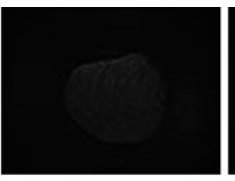

image430

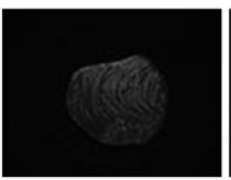

image470

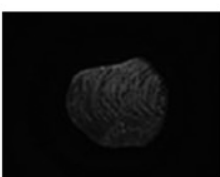

image510

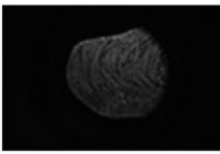

image590

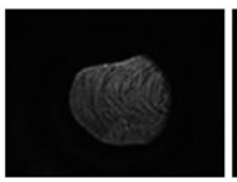

image630

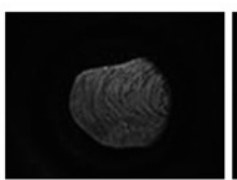

image670

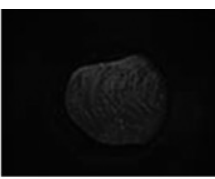

image435

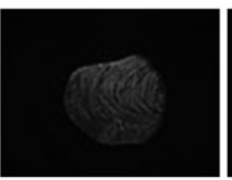

image475

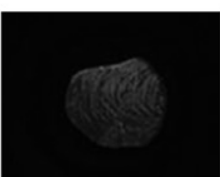

image515

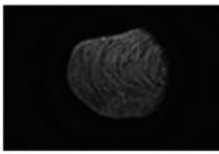

image595

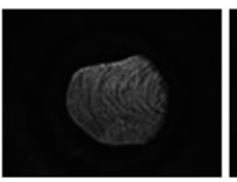

image635

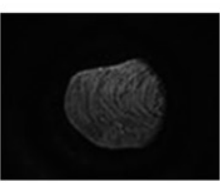

image675

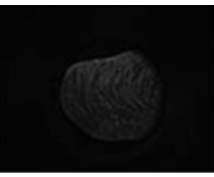

image440

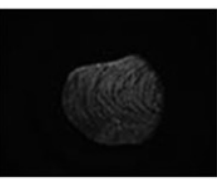

image480

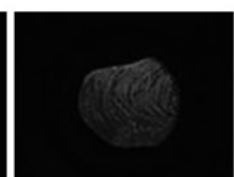

image520

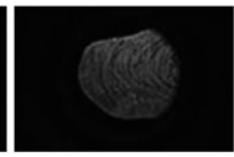

image600

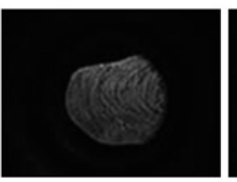

image640

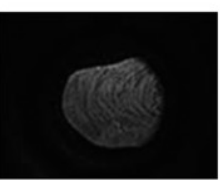

image680

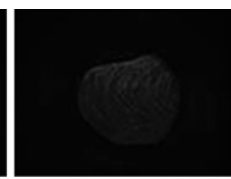

image445

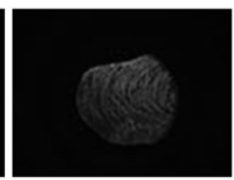

image485

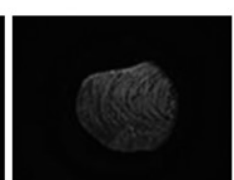

image525

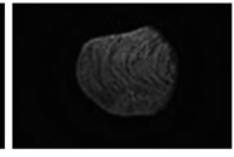

image605

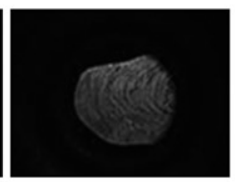

image645

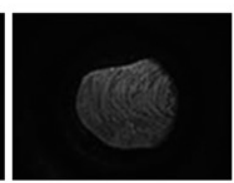

image685

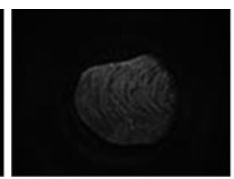

image450

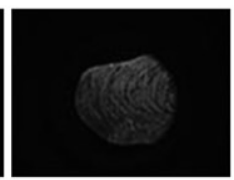

image490

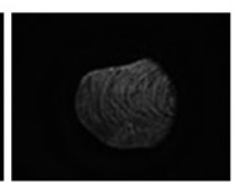

image 530

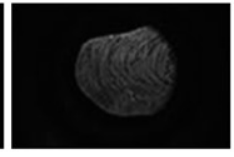

image610

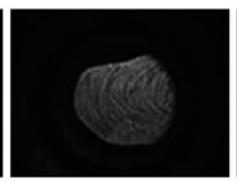

image650

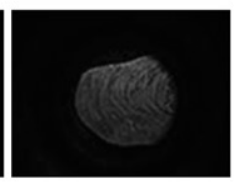

image690

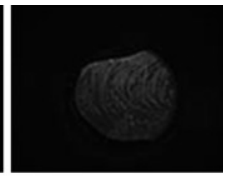

image455

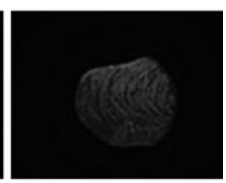

image495

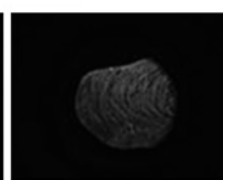

image535

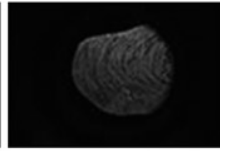

image615

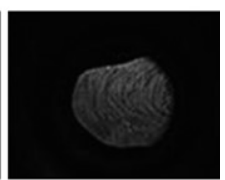

image655

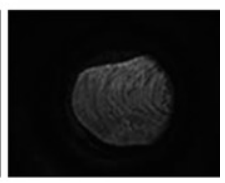

image695

Fig. 2. Hyperspectral image slices representing all light reflected in $5 \mathrm{~nm}$ band widths (stalagmite UD).

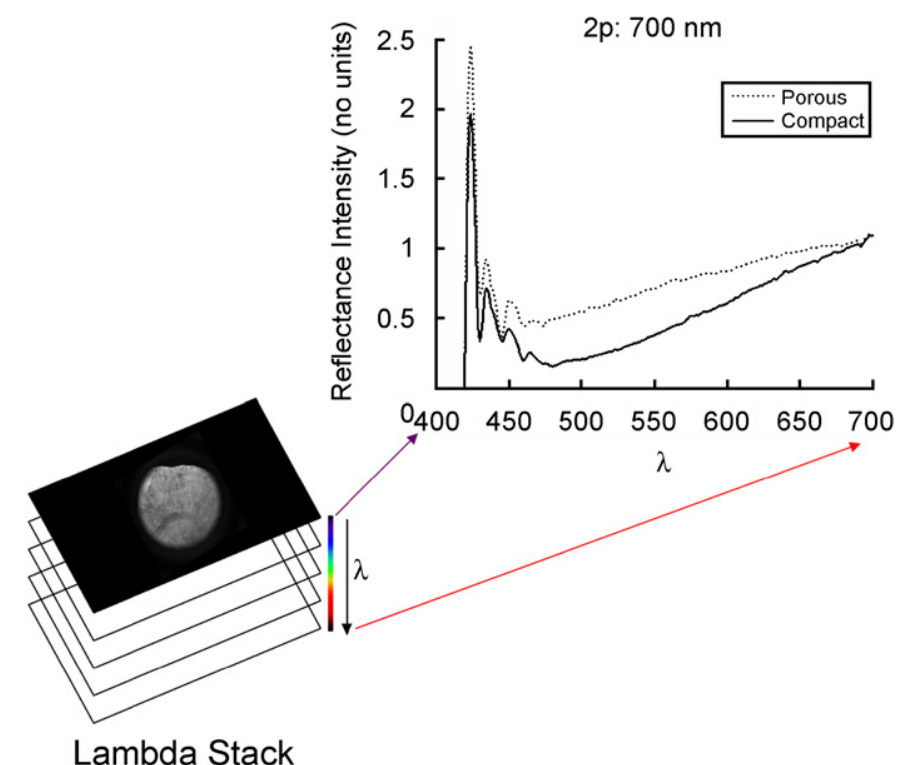

Lambda Stack

Fig. 3. An example of a Lambda stack of image slices and how graphs of reflectance peaks are obtained for any area on the image. and reflectance spectra using stalagmites and to suggest potential future analytical applications for this technique in speleothem research. In particular the key questions that may be addressed by hyperspectral imaging are:

(1) What do the visible reflectance spectra ${ }_{H}$ look like and are there common features within a single stalagmite or between different stalagmites of different ages, from different caves?

(2) What is the best waveband for identifying laminae?

(3) What do the near infrared (NIR) spectra ${ }_{\mathrm{H}}$ look like?

\section{Materials and methods}

In order to demonstrate these applications, hyperspectral images of a set of stalagmites have been obtained using a high-sensitivity 12-bit monochrome digital camera (QImaging Retiga Exi) and two LCD programmable interference filters VariSpec (Cambridge Research Instruments), one covering the visible range $420-720 \mathrm{~nm}$ and the other the NIR range $650-1100 \mathrm{~nm}$. The filters can be configured 
to implement any narrow (approx. $7 \mathrm{~nm}$ ) Gaussian bandpass filter within their respective wavelength ranges. The camera quantum efficiency and the filter transmittance vary as a function of wavelength, resulting in total sensitivity of the system, for example $6 \%$ at $450 \mathrm{~nm}, 30 \%$ at $550 \mathrm{~nm}$ and $40 \%$ at $700 \mathrm{~nm}$. To ensure that a sufficient number of photons reflected from the sample are collected by the camera, the acquisition times were varied as a function of wavelength, from $17 \mathrm{~ms}$ to $1.3 \mathrm{~s}$ per image. The filters and the camera were controlled using a standard notebook computer running custom software (this software was developed "in-house" by Ela Claridge). The samples were illuminated using a halogen light source diffused by an integrating sphere (ProLite, UK) coated with Spectralon $^{\mathrm{TM}}$. Images were acquired at two different magnifications, macro (see Section 3.1) and micro (see Section 3.2) (this approximately equates to $\times 3$ magnification). At the macro scale, the samples were placed within the halfsphere. At the micro scale, the illumination was provided by a 3 in port with light falling obliquely at the sample. In both cases, the camera objective was oriented approximately perpendicular to the polished surface of the sample. Following the acquisition, the spectral $_{\mathrm{H}}$ data was processed to remove the effects of the light source, imaging system and acquisition time. Following this correction, it was seen that peaks in the spectra ${ }_{\mathrm{H}}$ data obtained at less than $470 \mathrm{~nm}$ were due to instrumental artefacts and so not presented here. Black and white images have been obtained at $5 \mathrm{~nm}$ spectral intervals with a circular field of view of $3^{\prime \prime}$. The same set-up has been used for research on diagnostic imaging of human tissues including the retina (Styles et al., 2006) and the colon (Hidovic and Claridge, 2005).

It is worth noting that during this image capture process, there are a number of factors to consider. These include some degree of specular reflection (which have been minimised by ensuring that the light source is at an angle with respect to the camera axis), scattering (which is likely restricted to a thin layer of the sample as the sample is highly polished) and excitation of fluorescence emission due to light hitting the surface (this is usually much lower than the remitted/reflected light and has little effect on the kinds of spectra collected). In the absence of pure calcite from which to calibrate our obtained spectra $_{\mathrm{H}}$, the spectral $_{\mathrm{H}}$ data were processed by standardisation with a "Spectralon calibration tile" to remove the effects of light source, imaging system and acquisition time. Details are as follows. The camera, the light source and the VariSpec filters are "factory calibrated" and, specifically, for each we have, as a function of wavelength, respectively, quantum efficiency $\left(\mathrm{QE}(\lambda)\right.$, radiance $\left(I_{0}(\lambda)\right)$ and filter transmission rate $(\mathrm{FT}(\lambda))$. The magnitude recorded on a camera sensor (image value, IM) is a function of the sample reflectance $R(\lambda)$, and the parameters of the imaging system, QE, $I_{0}$ and FT:

$\operatorname{IM}(\lambda)=\int_{\lambda} R(\lambda) I_{0}(\lambda) \mathrm{QE}(\lambda) \mathrm{FT}(\lambda) \mathrm{d} \lambda$.
By deconvolving IM with $I_{0}(\lambda), \mathrm{QE}(\lambda)$ and $\mathrm{FT}(\lambda)$, which are available as a function of wavelength from instrument calibration, the "pure" sample reflectance spectrum $R(\lambda)$ can be recovered at each point of the hyperspectral image. The correctness of removing the effects of light source and imaging system on the sample spectrum was verified by imaging a Spectralon calibration tile, which has a flat (to within $3 \%$ ) reflectance spectrum across all the wavelengths in the visible and NIR range. If the process is correct, the computed reflectance spectrum of the tile after deconvolution should also be flat.
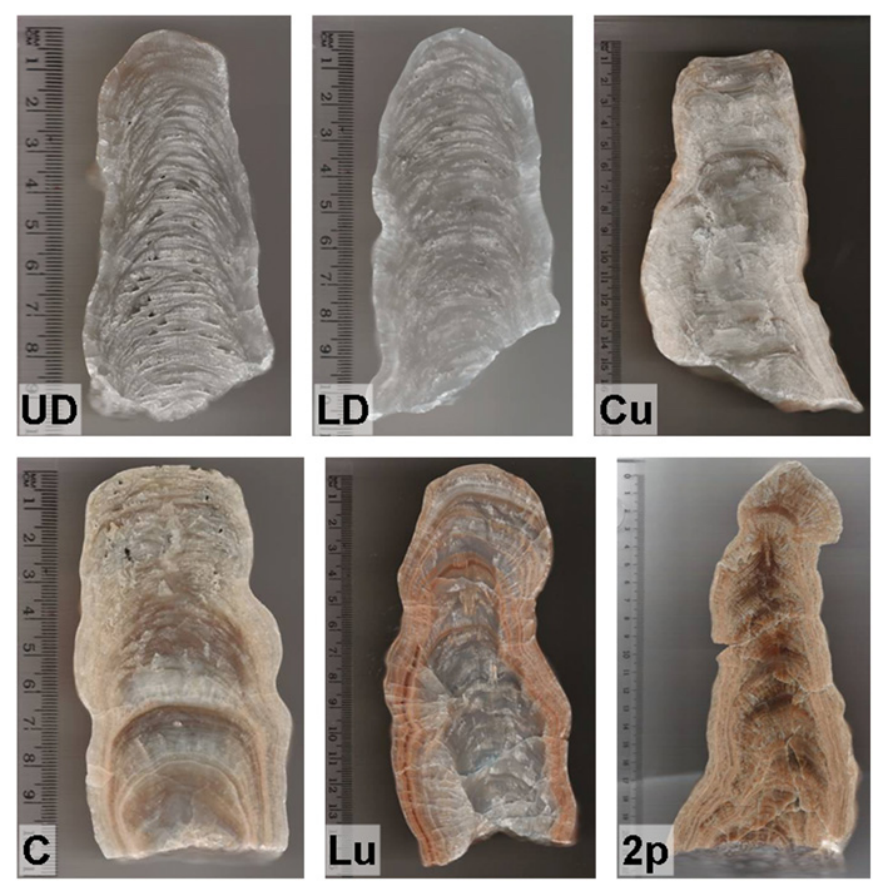

Fig. 4. Speleothems used in this report, UD; LD; Cu; C; Lu and 2p (UD, $\mathrm{LD}, \mathrm{Cu}$ and $\mathrm{Lu}$ were taken from Karaca Mağarasi; $\mathrm{C}$ and $2 \mathrm{p}$ were taken from Akçkale Mağarası).

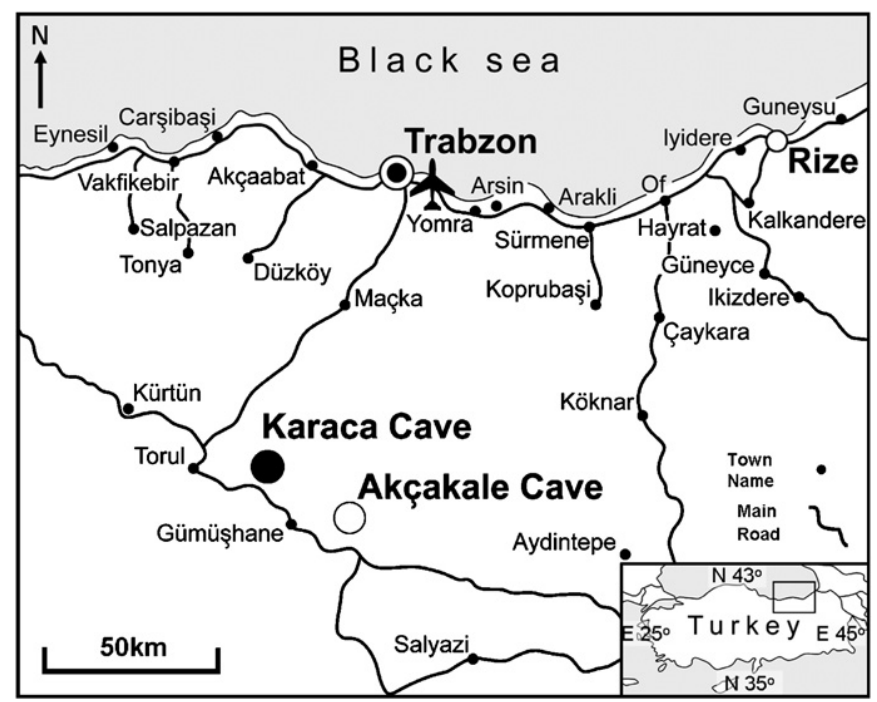

Fig. 5. Study area location map. 
The stalagmites used in this study (Fig. 4) were obtained from two caves, Karaca Mağarası (Karaca cave) and Akçakale Mağarası (Akçakale cave) in the Gümüşhane Province of NE Turkey (Fig. 5) in July 2005. Both caves are developed in Liassic-Lower Cretaceous limestone layers (Nazik, 1994). Karaca Cave, a show cave opened in 1990, is predominantly a dry cave, located $22 \mathrm{~km}$ north west of Gümüşhane (Aygen, 1999) at an altitude of $1536 \mathrm{~m}$, it has a total length of $256 \mathrm{~m}$ and a depth of up to $15 \mathrm{~m}$ below the entrance (Nazik, 1994). Above the cave there is little soil development with anything from $100 \%$ bedrock and active scree to $100 \%$ soil cover (the latter being found only in isolated patches and composed of a single-horizon containing angular fragments, with a depth around $5 \mathrm{~cm}$ ).
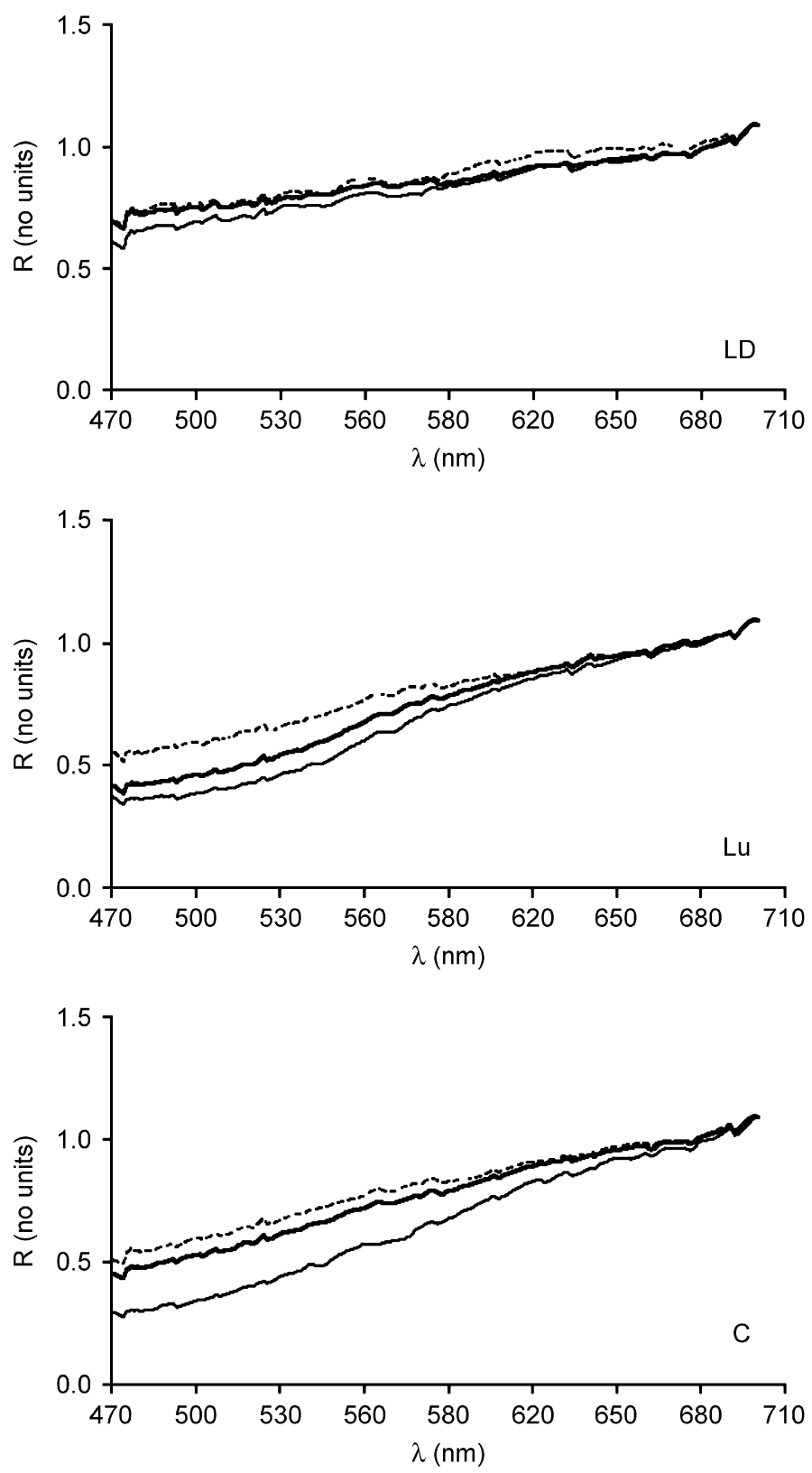

Akçakale cave, located $6 \mathrm{~km} \mathrm{SE}$ of the town of Gümüşhane at an elevation of $1530 \mathrm{~m}$, is much larger than Karaca and generally appears to be wetter, with an increased number of faster flowing drips and large waterfalls actively forming extensive flowstones. Above the cave, soil cover is more extensive $(\sim 30 \mathrm{~cm}$ depth) than above Karaca, with anything from stable vegetated scree (in a dried up river bed) to vegetated soil either side of this river bed. Also present is a ploughed area of land and tree growth surrounding the site.

The northeast Black Sea coastal region of Turkey is characterised by the highest precipitation totals of Turkey with annual totals of up to $1180 \mathrm{~mm}$ (Unal et al., 2003), predominantly due to orographic ascent of on-shore
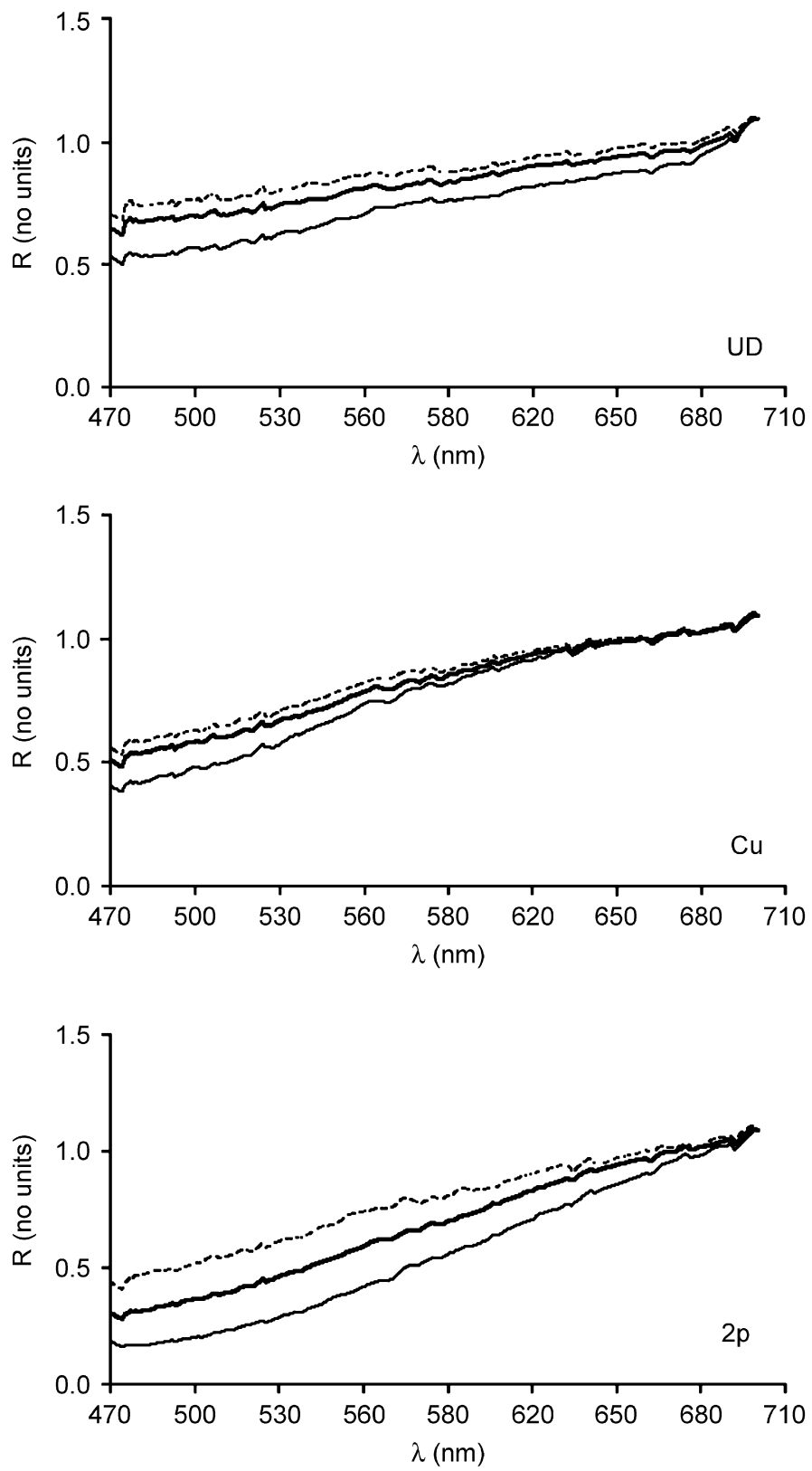

Fig. 6. Reflectance Spectra ${ }_{\mathrm{H}}$ obtained from areas of porous and compact calcite for each stalagmite. $R=$ reflectance intensity (no units). In the figures dotted line represents WPC; the solid narrow line represents DCC and the solid thick line represents the whole image. 
sea-breezes and cyclonic activity by the Pontic Mountain range (a narrow east-west trending ridge of mountains running parallel to the Black Sea Coast). Further, it has extremes of temperature, which typically range from a min of $-2{ }^{\circ} \mathrm{C}$ to a maximum of $25^{\circ} \mathrm{C}$, resulting in a strong seasonality of climate and thus strong potential to obtain annually laminated speleothems from this region.

\section{Results and discussions}

\subsection{Spectra ${ }_{H}$ in the visible range}

Fig. 6 shows the reflectance spectra ${ }_{\mathrm{H}}$ obtained from porous sections of lamina (white porous calcite: WPC) and more compact sections of lamina (dark compact calcite: DCC). The key features for each stalagmite are summarised in Table 1. Table 2 gives the details of range-finder radiocarbon dates of the imaged areas of these samples.
From these figures, it is evident that the reflectance spectra $_{\mathrm{H}}$ of compact and porous calcite are most different in all of the samples between $\sim 470$ and $590 \mathrm{~nm}$ (this extends to $680 \mathrm{~nm}$ for samples such as $2 \mathrm{p}$ ). Thus for the purposes of lamina counting, these bands of wavelengths may produce more usable images and quantitative spectral data than conventional imaging techniques. Despite the different ages of the stalagmites used and the fact that they have come from different caves, overall the spectra ${ }_{H}$ look remarkably similar from one sample to another as highlighted in Table 1.

These results suggest that reflectance is dominated calcite reflectance, with the greatest differences being between spectra $_{\mathrm{H}}$ of porous and compact calcite within a sample and not between samples themselves. However further work is necessary to build up a wider library of spectra $_{\mathrm{H}}$ (for example aragonite) from stalagmites from other regions to identify other common features in stalagmite spectra $\mathrm{H}_{\mathrm{H}}$.

Table 1

Key hyperspectral features of this set of stalagmites

\begin{tabular}{|c|c|c|c|}
\hline Stalagmite & $\begin{array}{l}\text { Hydrological } \\
\text { setting in the cave }\end{array}$ & $\begin{array}{l}\text { DCP corrected age } \\
\text { (yrs BP) }\end{array}$ & Key hyperspectral characterisitics \\
\hline $\mathrm{Cu}$ (Karaca cave) & NSSF/fossil & $\begin{array}{l}\text { T: } 3294 \pm 210 \\
\text { B: } 8546 \pm 380\end{array}$ & $\begin{array}{l}\text { Lamina most clearly defined between: } 475-570 \mathrm{~nm} \text {; spectra dominated by calcite } \\
\text { reflection }\end{array}$ \\
\hline Lu (Karaca cave) & $\mathrm{WCD} /$ fossil & $\begin{array}{l}\mathrm{T}: 3332 \pm 210 \\
\mathrm{~B}: 25782 \pm 3370\end{array}$ & $\begin{array}{l}\text { Lamina most clearly defined between: } 480-570 \mathrm{~nm} \text {; spectra dominated by calcite } \\
\text { reflection }\end{array}$ \\
\hline LD (Karaca cave) & $\mathrm{SSF} /$ fossil & B: $13555 \pm 700$ & $\begin{array}{l}\text { Lamina most clearly defined between: } 450-470 \mathrm{~nm} \text { no major difference between } \\
\text { WPC and DCC over range of wavelengths observed in other samples; spectra } \\
\text { dominated by calcite reflection }\end{array}$ \\
\hline UD (Karaca cave) & $\mathrm{SSF} /$ fossil* & - & $\begin{array}{l}\text { Lamina most clearly defined between } 480-570 \mathrm{~nm} \text {; spectra dominated by calcite } \\
\text { reflection }\end{array}$ \\
\hline C (Akçakale cave) & NSSF/active* & - & $\begin{array}{l}\text { Lamina most clearly defined between } 460-580 \mathrm{~nm} \text {; spectra dominated by calcite } \\
\text { reflection }\end{array}$ \\
\hline 2p (Akçakale cave) & WCD/active* & - & $\begin{array}{l}\text { Lamina most clearly defined between } 480-675 \mathrm{~nm} \text {; spectra dominated by calcite } \\
\text { reflection }\end{array}$ \\
\hline
\end{tabular}

SSF: soda straw fed stalagmites; NSSF: non-soda straw fed stalagmites; WCD: stalagmites growing within curtains/draperies. T: top of area imaged; B: base of area imaged. (DCP corrected age: radiocarbon age corrected for a dead carbon percentage of $20 \%$; $*$ indicates these samples are awaiting U-Th dates but are believed to be either fossil or actively forming stalagmites as indicated).

Table 2

Range-finder radiocarbon dates of CU, Lu and LD covering the area of the stalagmites used for image analysis

\begin{tabular}{|c|c|c|c|c|c|c|c|}
\hline Sample & $\begin{array}{l}\text { Location in } \\
\text { imaged area }\end{array}$ & SUERC lab no. & $\mathrm{C}^{14}$ age (yrs BP) & $\begin{array}{l}1 \text { sigma } C^{14} \text { age } \\
(\text { yrs } \mathrm{BP})\end{array}$ & $\delta^{13} \mathrm{C}_{\mathrm{VPDB}} \pm 0.1 \%$ & $\begin{array}{l}\text { DCP Corrected } \\
\text { Age (yrs BP) }\end{array}$ & Error \\
\hline $\mathrm{Cu} 1$ & $\mathrm{~T}$ & SUERC-11387 & 5087 & 35 & -7.9 & 3294 & 210 \\
\hline $\mathrm{Cu} 2$ & B & SUERC-11399 & 9635 & 36 & -7.6 & 8546 & 380 \\
\hline Lul & $\mathrm{T}$ & SUERC-11675 & 5124 & 35 & -6.6 & 3332 & 210 \\
\hline $\mathrm{Lu} 2$ & B & SUERC-11687 & 27568 & 250 & -3.9 & 25782 & 3370 \\
\hline LD1 & $\mathrm{T}$ & SUERC-11688 & 11359 & 35 & -6.8 & 9565 & 430 \\
\hline LD2 & $\mathrm{B}$ & SUERC-11699 & 15350 & 60 & -5.5 & 13555 & 700 \\
\hline
\end{tabular}

$\mathrm{T}$ : top of area imaged; B: base of area imaged. 

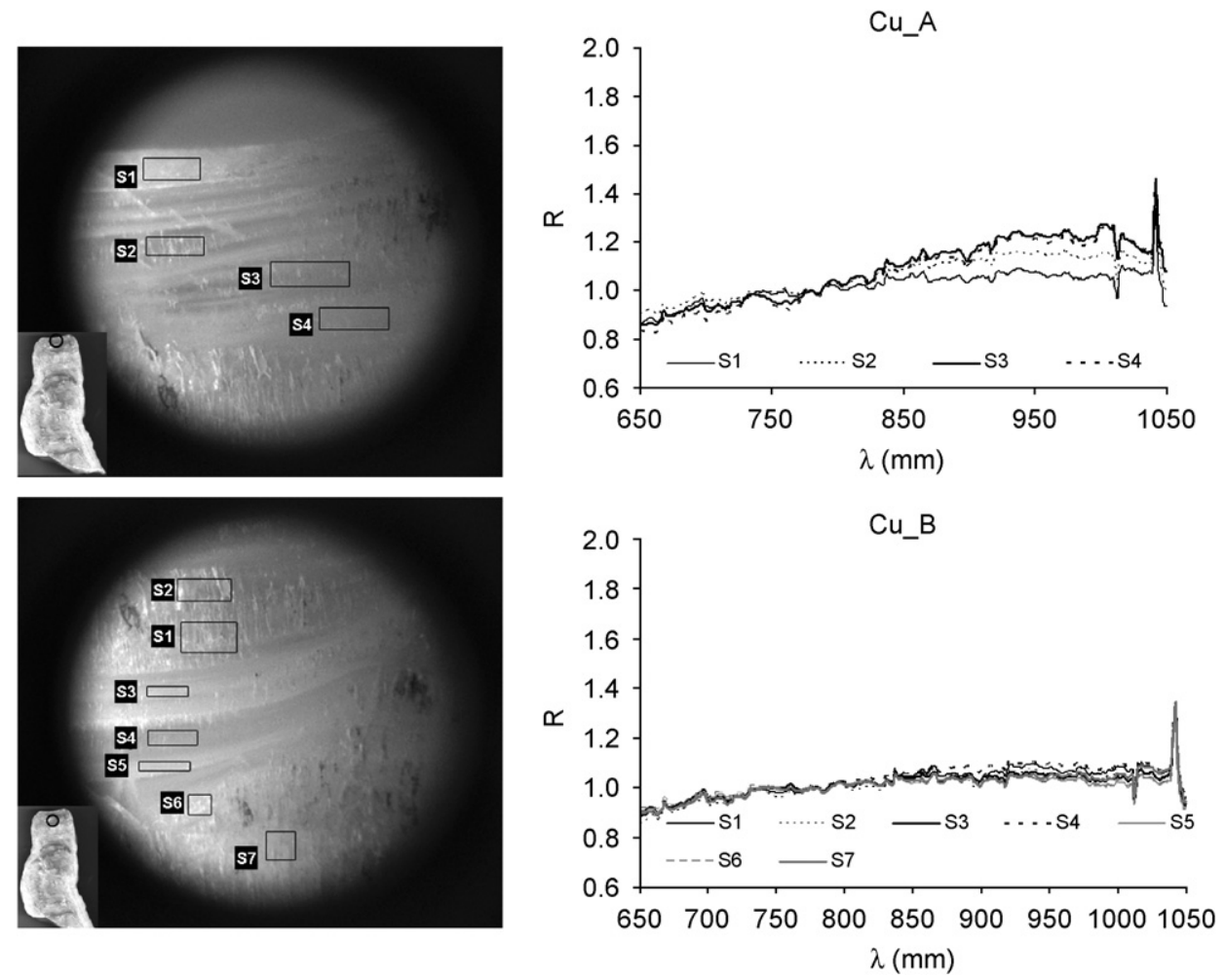

Fig. 7. NIR reflectance spectra $\mathrm{H}_{\mathrm{H}}$ of $\mathrm{Cu}$ (the location of each spectra $_{\mathrm{H}}(\mathrm{S} 1, \mathrm{~S} 2$, etc.) are indicated in the hyperspectral image).
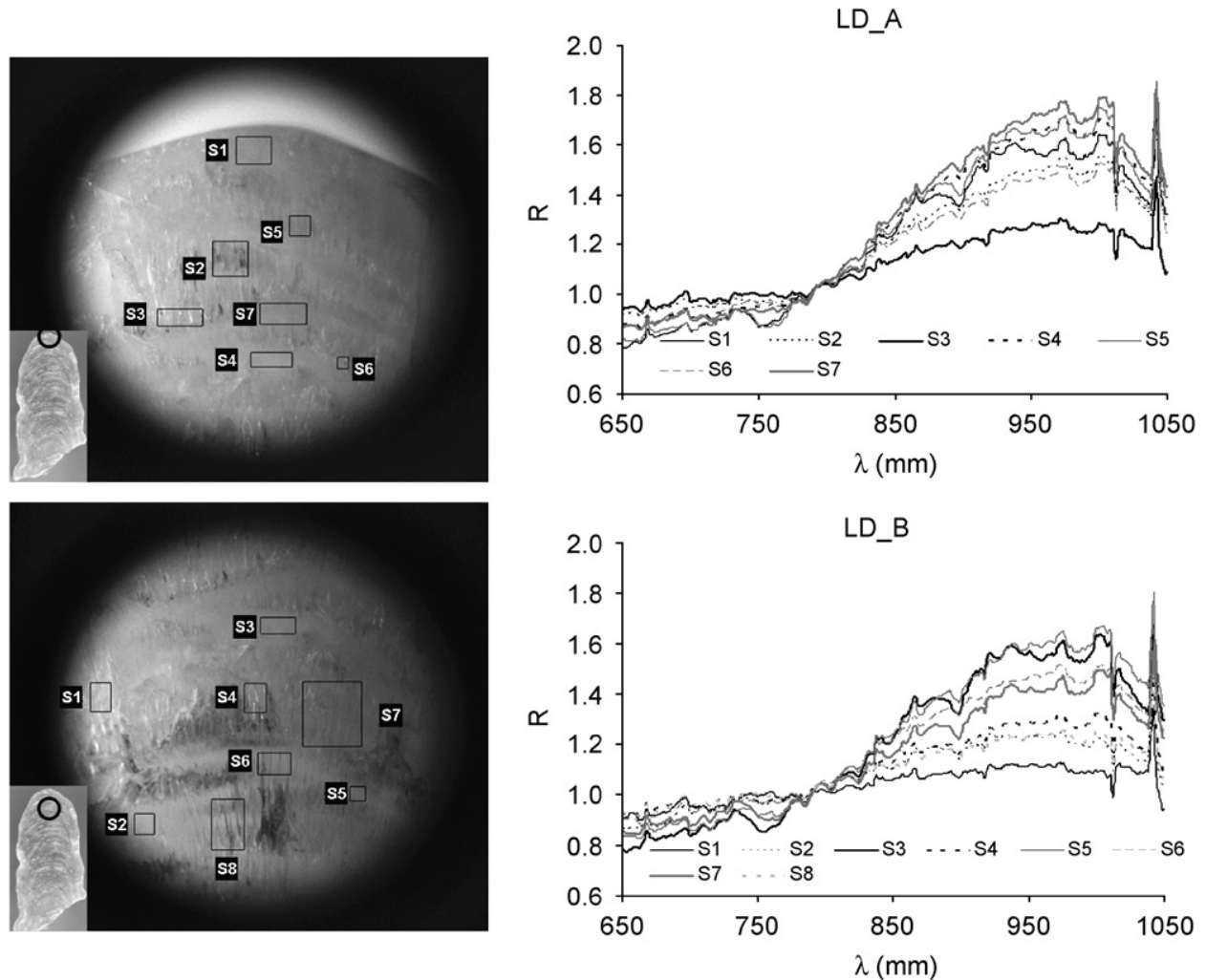

Fig. 8. NIR reflectance spectra ${ }_{H}$ of LD. 


\subsection{Spectra $_{H}$ of the NIR spectral range}

Two of the stalagmites $(\mathrm{Cu}$ and $\mathrm{LD})$ were imaged in order to collect reflectance spectra $\mathrm{H}_{\mathrm{H}}$ in the NIR, the results of which are shown in Figs. 7 and 8. The top image slice is included to show the locations at which the spectra $\mathrm{H}_{\mathrm{H}}$ were obtained. In the NIR, a $\mathrm{H}_{2} \mathrm{O}$ absorption band would be expected at around $900-1100 \mathrm{~nm}$. Thus any trough in the reflectance spectra ${ }_{\mathrm{H}}$ over these wavelengths could indicate the presence of water within the stalagmite. In $\mathrm{Cu}$ there is no clear decrease in reflectance intensity at these wavelengths; however, in LD there is, demonstrating the presence of $\mathrm{H}_{2} \mathrm{O}$ trapped within LD (possibly as fluid inclusions).

There is great potential, therefore, to map out areas of a stalagmite where fluid inclusions are present to a greater or lesser extent. This may be done in the future by building up a spectral library of characteristic water reflectance spectra $_{\mathbf{H}}$ and using custom software to asses how much of the stalagmites spectra ${ }_{\mathrm{H}}$ at any one point on the image is contributed to by this spectra $\mathrm{H}_{\mathrm{H}}$. False colour may be given to the stalagmite images to highlight areas of $\mathrm{H}_{2} \mathrm{O}$ as potential areas of fluid inclusions. This would aid all studies in using fluid inclusions to obtain $\delta^{18} \mathrm{O}$ data. These have been very preliminary experiments, to see whether there are any spectral differences between different constituents of the sample.

\section{Conclusions}

Our results highlight the following:

(1) Spectra $_{\mathrm{H}}$ obtained for these calcite stalagmites are similar between a group of stalagmites of different ages, from different hydrological settings within a cave and between those from different caves.

(2) The largest differences in relative reflectance between areas of DCC and WPC are in the range $470-590 \mathrm{~nm}$ (this may extend to $680 \mathrm{~nm}$ for some of the stalagmites).

(3) Imaging in the NIR demonstrates a decrease in reflection at water absorbance wavelengths. This suggests there is potential for mapping $\mathrm{H}_{2} \mathrm{O}$. Extending these observations further into the IR part of the spectrum is a point for future research.

\section{Acknowledgements}

The authors would like to thank colleagues of the "Environmental Change in North East Turkey" project in the UK and Turkey, staff at Karaca Cave and at Gümüşhane government department of tourism for access to both caves. Thanks also to AWM Visualisation and Imaging Network, and NERC RCL facility. Thanks also to three anonymous reviewers for their comments and suggestions that helped improve the manuscript.

\section{References}

Ayalon, A., Bar-Matthews, M., Kaufman, A., 1999. Petrography, strontium, barium and uranium concentrations, and strontium and uranium isotope ratios in speleothems as paleoclimatic proxies: Soreq Cave, Israel. The Holocene 9 (6), 715-722.

Aygen, T. (Ed.), 1999. Karaca Cavern, Torul-Gumushane. The Shell Company of Turkey, Ilgi. Istanbul.

Baker, A., Smart, P.L., Edwards, R.L., Richards, D.A., 1993. Annual banding in a Cave Stalagmite. Nature 364, 518-520.

Bar-Matthews, M., Matthew, A., Ayalon, A., 1991. Environmental controls of speleothem mineralogy in a karstic dolomitic terrain (Soreq Cave, Israel). Journal of Geology 99, 189-207.

Fairchild, I.J., 2002. High-resolution speleothem trace element records: potential as climate proxies. In: Carrasco, F., Durán, J.J., Andreo, B. (Eds)., Karst and Environment, pp. 377-380.

Frisia, S., Borsato, A., Fairchild, I.J., McDermott, F., 2000. Calcite fabrics, growth mechanisms, and environments of formation in speleothems from the Italian Alps and Southwestern Ireland. Journal of Sedimentary Research 70, 1183-1186.

Genty, D., 1993. Mise en évidence d'alternances saisonnières dans la structure interne des stalagmites. Intérêt pour la reconstitution des paléoenvironnements continentaux. Comptes Rendus Academy of Science, Paris 317 (Série II), 1229-1236.

Genty, D., Baker, A., Vokal, B., 2001. Intra- and inter-annual growth rate of modern stalagmites. Chemical Geology 176, 191-212.

Gomez, R.B., 2002. Hyperspectral imaging: a useful technology for transportation analysis. Optical Engineering 41 (9), 2137-2143.

Hamid Muhammed, H., 2005. Hyperspectral image generation, processing and analysis. Ph.D. thesis, Uppsala University, Centre for Image Analysis.

Haubrock, S., Chabrillat, S., Kaufmann, M., 2005. Application of hyperspectral imaging and laser scanning for the monitoring and assessment of soil erosion in a recultivation mining area. In: Erasmi, S., Cylfka, B., Kappas (Eds.), Remote Sensing \& GIS for Environmental Studies, vol. 113. Göttinger Geographische Abhandlungen, Göttingen.

Hidovic, D., Claridge, E., 2005. Modelling and validation of spectral reflectance for the colon. Physics in Medicine and Biology 50, 1071-1093.

Kendall, A.C., Broughton, P.L., 1978. Origin of fabrics in speleothems composed of columnar calcite crystals. Journal of Sedimentary Petrology 48, 519-538.

McDermott, F., 2004. Paleo-climate reconstruction from stable isotope variations in spleothems: a review. Quaternary Science Reviews 23, 901-918.

McGarry, S.F., Caseldine, C., 2004. Speleothem palynology: an undervalued tool in quaternary studies. Quaternary Science Reviews 23 (2324), 2389-2404.

McLaugh, E.L., Girard, J.M., Denes, L.J., 2001. Simplified hyperspectral imaging for improved geologic mapping of mine slopes. In: Meech, J.S., Viega, S.M., LeClair, S.R., Maguire, J.F. (Eds.), Proceedings of the Third International Conference on Intelligent Processing and Manufacturing of Materials. Vancover, BC.

Nazik, L.E.A., 1994. Natural caves of Gümüşhane and Bayburt region. In: Second Symposium of Speleology, MTA., Ankara, Turkey.

Perrette, Y., Genty, D., Destombes, J.-L., Delannoy, J.-J., Quinif, Y., 1997. Characterisation of Speleothem Crystalline Fabrics by Spectroscopic and Digital Image Processing Methods. UIS Conges. Choranche, Vercors, France.

Perrette, Y., Delannoy, J.J., Desmet, M., Lignier, V., Destombes, J.L., 2005. Speleothem organic matter content imaging. The use of a fluorescence index to characterise the maximum emission wavelength. Chemical Geology 214, 193-208.

Pinnel, N., Heege, T., Zimmermann, S., 2004. Spectral Discrimination of Submerged Macrophytes in Lakes using Hyperspectral Remote Sensing Data. SPIE Proc, Ocean Optics XVII, Fremantle. SPIEThe International Society for Optical Engineering, pp. 1-16.

Proctor, C.J., Baker, A., Barnes, W.L., 2002. A three thousand year record of N Atlantic climate. Climate Dynamics 19, 449-454. 
Ribes, A.C., Lundberg, J., Waldron, D.J., Vesely, M., Damaskinos, S., Guthrie, S.I., Dixon, A.E., 2000. Photoluminescence imaging of speleothem microbanding with a high-resolution confocal scanning laser microscope. Quaternary International 68-71, 253-259.

Roberts, M.S., Smart, P.L., Hawkesworth, C.J., Perkins, W.T., Pearce, N.J.G., 1999. Trace elements variations in coeval Holocene speleothems from GB Cave, southwest England. The Holocene 9 (6), 707-713.

Rousseau, L., Bouloussa, O., de Lumley, H., 1993. Evaluation of the respective influence of humic acids and ferric oxides upon the colouring of flowstones. Geochimie 317 (2), 367-370.

Rozanski, K., Araguas-Araguas, L., Gonfianti, R., 1992. Relationship between long-term trends of oxygen-18 isotope composition of precipitation and climate. Science 258, 981-985.

Styles, I.B., Calcagni, A., Claridge, E., Orihuela Espina, F., Gibson, J.M., 2006. Quantitative analysis of multispectral fundus images. Medical Image Analysis 10 (4), 578-597.
Tan, M., Baker, A., Genty, D., Smith, C., Esper, J., Cai, B., 2006. Applications of stalagmite laminae to paleoclimate reconstructions: comparison with dendrochronology/climatology. Quaternary Science Reviews 25, 2103-2117.

Unal, Y., Kindap, T., Karaca, M., 2003. Redefining the climate zones of Turkey using cluster analysis. International Journal of Climatology 23, $1045-1055$.

White, W.B., 1981. The National Speleological Society Bulletin 43, 20-26.

White, W.B., Brennan, E.S., 1989. Luminescence of speleothems due to fulvic acid and other activators. In: Proceedings of the 10thInternational Congress of Speleology, pp. 212-214.

Xiaoguang, Q., Dongsheng, L., Tungsheng, L., Ming, T., Tieying, L., Jinpo, L., Zhaoyan, G., Houyuan, L., Zhongli, D., Zhengtang, G., Jiaqi, L., Gaozhong, N., 1998. Grey characteristics of microbanding of stalagmite in Shihua Cave, Beijing and its climatic significance. Science in China 41 (2), 151-157. 